\title{
Whom do nascent ventures search for? Resource scarcity and linkage formation activities during new product development processes
}

\author{
Andrea M. Herrmann • Cornelia Storz $(\mathbb{D} \cdot$ Lukas Held
}

\begin{abstract}
External linkages allow nascent ventures to access crucial resources during the process of new product development. Forming external linkages can substantially contribute to a venture's performance. However, little is known about the paths of external linkage formation, as well as the circumstances that drive the choice to pursue one rather than another path. This gap deserves further investigation, because we do not know whether insights developed for incumbent firms also apply to nascent ventures: To address this gap, we explore a novel dataset of 370 venture creation processes. Using sequence analyses based on optimal matching techniques and cluster analyses, we reveal that nascent ventures pursue one of overall four distinct paths of linkage formation activities during new product development. Contrary to the findings of the strategy literature, we find that if nascent ventures engage in external linkages at all, they do not combine exploration- and exploitation-oriented linkages but form either exploration- or exploitation-oriented linkages.
\end{abstract}

A. M. Herrmann · L. Held

Innovation Studies, Copernicus Institute of Sustainable

Development, Utrecht University, Utrecht, Netherlands

A. M. Herrmann

Max-Planck-Institut für Gesellschaftsforschung, Cologne, Germany

C. Storz $(\bowtie)$

Economic Institutions, Innovation and East Asian Development, Faculty of Business and Economics, University of Frankfurt, Frankfurt, Germany

e-mail: storz@wiwi.uni-frankfurt.de
Additional regression analyses highlight the circumstances that lead nascent ventures to pursue one rather than the other pathways. Taken together, our analyses point out that resource scarcity constitutes an important factor shaping the linkage formation activities of nascent ventures. Accordingly, we show that nascent ventures tend not to optimize by adding complementary knowledge to the firm's knowledge base but rather to extend the existing knowledge base-a strategy which we call bricolage.

Keywords Nascent ventures $\cdot$ Linkages $\cdot$ New product development processes $\cdot$ Research and market linkages . Sequence analyses - Optimal matching techniques

JEL classifications $\mathrm{L} 26 \cdot \mathrm{O} 31 \cdot \mathrm{O} 32 \cdot \mathrm{M} 13$

\section{Introduction}

Forming linkages to external partners during the new product development process may substantially contribute to an incumbent firms' performance (Chapman et al. 2018; Dahlander et al. 2016; Leiponen and Helfat 2011; Meyskens and Carsrud 2013), including greater product novelty and better product performance (Hoang and Rothaermel 2010; Nieto and Santamaría 2007; Rothaermel 2001; Soh 2003). More concretely, the strategy literature suggests that the resource base of a firm may explain the choice of linkages (Ahuja 2000; Alvarez and Barney 2001; Eisenhardt and Schoonhoven 1996): Distinct strategic needs, in particular the need to 
complement existing firm resources and to access heterogeneous knowledge, drive the choice of linkages (Alvarez and Barney 2001; Ireland et al. 2002). In other words, the strategy literature teaches us that established firms build up external linkages in an optimizing approach (Desa and Basu 2013).

One way to conceptualize the complementarity of knowledge is to refer to the established distinction between the exploration and exploitation mode of learning (March 1991). Knowledge exploration is related to research activities which allow firms to discover something new (such as obtaining joint patents, developing and improving products, or defining new technical standards). Knowledge exploitation refers to the implementation, commercialization, and refinement of knowledge. These concepts have been extended to interfirm linkages and strategic alliances (Koza and Lewin 1998). Rothaermel and Deeds (2004) show, for example, that within strategic alliances, exploration alliances predict new product development, which then predict exploitation alliances to bring the products on the market; in other words, exploitation alliances complement the prior exploration phase. Linkages provide those resources which are lacking in the firm's knowledge base (Rothaermel 2001). Hence, the strategy literature assumes that linkage formation paths are characterized by (diverse) sequences of exploration and exploitation and that an important driver of firms to enter distinct linkages is the strategic need for complementary knowledge.

Empirically, the literature focuses on incumbent firms, such as listed firms (Stettner and Lavie 2014; Shi and Prescott 2011) or established ventures (Eisenhardt and Schoonhoven 1996; Rothaermel and Deeds 2004; Russo and Vurro 2010). However, while these studies provide us with a good understanding of linkage formation paths and their drivers for established ventures, evidence for nascent ventures is scarce. Yet nascent ventures differ in many respects from established ventures, most prominently with regard to their resource scarcity, i.e., managerial, financial, and informational scarcity (Ahuja 2000; van Burg et al. 2012). As early strategy choices have a long-lasting imprint on ventures (Mathias et al. 2015; Grilli et al. 2014; Bamford et al. 2000), these insights matter for strategic management scholars as it casts doubt on the implicit assumption that alliances are used to mobilize relevant resources by combining exploration and exploitation (Moeen and Mitchell 2020; Rothaermel and
Deeds 2004; Shi and Prescott 2011; Stettner and Lavie 2014; Koza and Lewin 1998; Holmqvist 2004; Greve 2007; Hill and Birkinshaw 2008; Russo and Vurro 2010), a strategy which Desa and Basu (2013: 28) have called an "optimization approach." This is why Hoang and Antoncic (2003) in their overview on linkage formation have called for more research to better understand the linkage formation process of nascent ventures (what they call the "network development processes"), and why Shi et al. (2012) argue that more work is needed on "what order or sequences" (p 182) are formed. The lack of research is particularly surprising in view of the ample literature highlighting that ventures increasingly rely upon external actors in their product development processes (Freitas et al. 2011; Powell et al. 1996).

In this paper, we seek to address this gap on (1) "how" and (2) "why" founders add linkages to their venture's resource base. Accordingly, we ask whether distinct paths of linkage formation to external partners during the new product development process of nascent ventures exist ("how"), and which circumstances drive a venture to pursue one rather than another path ("why"). The "how" allows us to understand how the linkage formation path evolves over time, while the "why" provides insights into the underlying drivers of these specific paths and hence into the core conditions which may be addressed by managers or policymakers. Given the central role of resources for a firm's competitiveness (Barney 1991), we argue that the resource scarcity of nascent ventures shapes both the paths and drivers of linkage formation during the new product development process - but in different ways than established by the strategy literature. While it is theoretically well established-and the basis for numerous policies - that small firms are resource scarce (Lee et al. 2010; Grilli and Murtinu 2018; van Burg et al. 2012; Cunha et al. 2014), we do not know whether and, if so, how resource scarcity shapes the exploration and exploitation linkage formation path of nascent ventures. By highlighting the crucial role of existing resources for the formation of distinct paths of linkage formation activities, we also respond to calls for more work on how scarce resources (Eisenhardt and Schoonhoven 1996) and the liability of newness (Shi and Prescott 2011) shape the linkage formation of nascent ventures.

Methodologically, we answer the two interlinked research questions on the "how" and "why" of external 
linkage formation during the new product development process with the help of sequence analyses - a novel method that was originally developed to decode the human genome. Sequence analyses are typically applied in a two-step procedure (Biemann et al. 2012; Held et al. 2018): In a first step, the similarities and, respectively, differences of sequences (in our case: of linkage formation paths) are identified through optimal matching techniques by comparing the various activities of all paths to each other over time. If the respective paths are not pursued randomly but follow systematic patters, a distinct set of the most frequently pursued paths can be discerned. In a second step, the most frequently pursued (or most representative) path to which each individual path belongs is used as the dependent variable in logistic regression analyses in order to understand which circumstances drive the path chosen (in our case: the formation of exploitation and exploration linkages).

Given that sequence analyses require a lot of timestamped information about the linkage formation activities undertaken during each process, we collected a novel dataset including new product development paths of 370 nascent ventures in Europe (UK, Germany, Italy, the Netherlands) and the USA. This database makes it possible to identify different approaches towards linkage formation choices from the beginning until the end of a venture's new product development process and to additionally differentiate between the two most common functions of linkage formation, i.e., exploration and exploitation.

Accordingly, the contribution of our paper is not only of a methodological but also of a theoretical nature. First, from a methodological perspective, our study adds to the existing literature on linkage formation of nascent ventures in new product development. To the best of our knowledge, we are the first to use sequence analyses for investigating linkage formation paths of nascent ventures and its underlying drivers. Given that sequence analyses make it possible to compare entire paths rather than individual moments over time, our analyses provide truly dynamic insights into how paths unfold over time; they do not dissect paths into probabilities of events at specific moments in time. We thus contribute new methodological insights to the entrepreneurship and product development literatures of how paths can be investigated in a dynamic way, taking into account sequences in linkage formation as a temporal construct.

Second, from a theoretical perspective, we contribute to the strategy literature on linkage formation paths and its underlying drivers by extending previous research which focused on incumbents and established ventures (Eisenhardt and Schoonhoven 1996; Rothaermel and Deeds 2004; Russo and Vurro 2010; Shi and Prescott 2011; Shi et al. 2012; Stettner and Lavie 2014). Most remarkably, and contrary to one of the core findings of the literature (Koza and Lewin 1998; Rothaermel and Deeds 2004; Russo and Vurro 2010; Shi and Prescott 2011; Stettner and Lavie 2014), we find that - if external linkages are formed at all-nascent ventures engage either in exploration or in exploitation linkages to develop new products with external partners. Hardly any venture in our sample has combined exploration- and exploitation-oriented linkages - neither in parallel nor subsequently. This finding challenges those strands of the literature which assume that innovative firms tend to form sequences of linkages and, in particular, first exploration- and then exploitation-oriented linkages in order to strategically optimize the firm's knowledge base (Burgers et al. 2008; Lee et al. 2010; Rothaermel and Deeds 2004; Shi and Prescott 2011). We furthermore show that nascent ventures hardly search for complementarity by adding heterogeneous knowledge (Alvarez and Barney 2001) but rather extend existing knowledge. We thus observe a behavior which, in line with Welter et al. (2016), we term as "bricolage," meaning that linkages by extending the resources which are "at hand" (Baker and Nelson 2005: 331). Our findings hereby contribute to a better understanding of the linkage formation strategies of nascent ventures: We show that the latter do not optimize their resources by complementing the existing knowledge base with "lacking" resources, but rather choose a bricolage approach by extending what is "at hand." This finding is surprising as heterogeneous resources have thus far been considered a basic condition for entrepreneurship (Alvarez and Barney 2001).

\section{Linkage formation by nascent ventures in new product development}

New product development and innovation affect a firm's competitiveness (Hoang and Rothaermel 2010; Nieto and Santamaría 2007; Rothaermel 2001), and linkages to external partners are an important means to gain access to new knowledge (Carayannopoulos and Auster 2010). With linkages, we refer to the "coming together of diverse interests and people to achieve a 
common purpose via interactions, information sharing, and coordination activities" (Jassawalla and Sashittal 1998, p. 239). To assess linkage formation paths and their drivers, we draw on recent research into new product development which highlights the ventures' resource scarcity. To build such a theoretical framework, we proceed in two steps. First, we develop propositions on how the most common linkage formation paths of nascent ventures may look like. Second, we theorize about the drivers that lead nascent ventures to pursue one rather than another path.

\subsection{Linkage formation paths of incumbent firms versus nascent ventures}

A small strand of an emerging literature within strategic management tries to understand possible paths of linkage formation. Most of this research relies empirically on incumbent firms and on the exploration-exploitation framework of organizational learning (March 1991), which Koza and Lewin (1998) have extended to firms' alliances. The underlying idea is that strategic alliances pursue different intentions (or "alliance intents") in exploitation or exploration, depending on the overall strategy portfolio (Koza and Lewin 1998). According to this framework, external linkages allow established firms to mobilize resources, but depending on the resources needed, the linkages fulfill different functions: They may either support knowledge exploration or knowledge exploitation. In line with this framework, we distinguish between exploration (i.e., research)-oriented linkages and exploitation (i.e., market)-oriented linkages to external partners.

With regard to their formation paths, several studies show that established firms chose and combine exploration- and exploitation-oriented linkages to enhance performance (Moeen and Mitchell 2020; Rothaermel and Deeds 2004; Shi and Prescott 2011; Stettner and Lavie 2014; Koza and Lewin 1998; Holmqvist 2004; Greve 2007; Hill and Birkinshaw 2008; Russo and Vurro 2010). Within this literature strand, only two papers have analyzed the ordering of linkage formation paths: Shi and Prescott (2011) identify seven clusters of linkage formation paths which, as they argue, are "rather planned, organized yet subject to opportunities that arise in the market place" (p. 1045). Rothaermel and Deeds (2004) find that explorationoriented linkages tend to be followed by exploitationoriented linkages. According to both studies, the underlying reason and strategy for combining both linkage types is that exploration-oriented linkages provide new knowledge, whereas exploitation-oriented linkages provide resources (such as knowledge about customers, markets, and distribution) to transform new knowledge into a marketable product, depending on the strategic needs.

Importantly, though, we expect that these findings for established firms cannot be transferred one-on-one to nascent ventures, because the latter are resource scarce (Van Burg et al. 2012). Recent research into the resource scarcity of ventures (Stenholm and Renko 2016; Welter et al. 2016) shows that their strategies cannot be conceived as a calculating search for missing resources, but rather as an approach of bricolage, because resource scarcity forces nascent ventures to rely on the means "at hand" (Baker and Nelson 2005: 331). Cunha et al. (2014) argue that it is the "accumulation of familiarity with and knowledge about the resource that makes possible the revelation of potential services waiting to be extracted" (p. 204). This leads us to expect that nascent ventures tend to extend familiar resources rather than to complement existing with unfamiliar ones.

While scarcity may be problematic with regard to a wide variety of resources (such as financial resources and networks), ${ }^{1}$ we here follow the paradigm of the strategic HRM literature, which argues that human resources are central to any venture because they shape its strategic orientation (Wright et al. 2001; Zhao et al. 2020). Given that nascent ventures do often, simply, not have the necessary manpower to search for, negotiate, and systematically collaborate with external actors in order to develop the new product jointly, the lack of human resources is considered to be a central barrier to linkage formation activities.

Extending these insights to the linkage formation paths of nascent ventures, we expect that their small organizational size in terms of human resources influences whether alliances can be formed at all (Almeida et al. 2003) - a sequence pattern which Shi and Prescott (2011) call "cipher sequence". In view of this resource scarcity, we expect, first, that the dominant path chosen

\footnotetext{
${ }^{1}$ The rather vague notion of resources and their value is considered a shortcoming of the resource-based view (Kraaijenbrink 2011). We therefore follow the reasoning of strategic human resource management, which argues that human capital and human resources are at the core of a firm's competitiveness (Wright et al. 2001) - also in line with prior work on alliances (Grilli and Murtinu 2018).
} 
by nascent ventures during their new product development process is not to form any linkages to external partners but to rather develop their new product internally. Second, if products can no longer be developed in-house, we expect that the human resource scarcity of nascent ventures leads them to form only one linkage type, namely, either exploration- or exploitationoriented linkages: a sequence which was called "unitary sequence" (Shi and Prescott 2011). The choice of forming only one linkage reflects the high costs associated with identifying trustworthy linkage partners. Given that each new linkage adds additional costs to the resource scarce venture (Desa and Basu 2013), we expect that the latter need to aim at cost minimization when forming external linkages. Hence, we expect human resource scarcity to not only make linkage formation challenging but also to stimulate distinct paths of linkage formation activities during the new product development process of nascent ventures. Based on this reasoning, we develop the following two propositions:

Proposition 1: During the new product development process, a frequently pursued path consists in developing the new product in-house without forming any linkages to external partners.

Proposition 2: If linkages to external partners are formed during the new product development process, a frequently pursued path consists in combining in-house development with just one linkage, namely, either exploration or exploitation linkages to external partners.

\subsection{Drivers of linkage formation paths of nascent ventures}

We argue that resource scarcity not only explains distinct paths of linkage formation but also helps to explain the underlying drivers of these paths. We develop a set of hypotheses about the "why," i.e., about the circumstances in which nascent ventures pursue any of these paths. In doing so, we build on our previous reasoning that a venture's resource scarcity chiefly determines its choice of linkage formation path.

As nascent ventures are resource scarce and external linkages entail costs, in particular search costs and costs of making connections to external parties (Hennart 1991), the degree of resource scarcity affects which paths can be pursued and which linkages can be formed. We therefore argue that the formation and choice of linkages needs to be understood as a trade-off between these costs and the resources available that allow for such a search. A fundamentally important condition that shapes a venture's opportunities to pursue a linkage formation path is its human resources. While also financial resources can limit a venture's opportunities as they are interrelated to hiring decisions (van Burg et al. 2012), recent evidence shows that it is in particular human capital which shapes the learning behavior of entrepreneurs (Zhao et al. 2020; Grilli et al. 2014) and, more specifically, the formation of alliances (Grilli and Murtinu 2018). Depending on the human resources available, opportunities to follow pathways creating and entering external linkages should therefore differ substantially across firms (Ahuja 2000; Hoang and Antoncic 2003).

Nascent ventures are extremely resource scarce as they often consist only of the entrepreneur herself. When nascent ventures are of such small size, the entrepreneur herself needs to be a jack-of-all-trades. With regard to the linkage formation path chosen, she does not only carry out the search of potential external partners but also is the one who takes strategic decisions about whether, or not, to form external linkages. The search for external partners thus causes particularly high opportunity costs, because external search activities take the entrepreneur's attention away from other internal activities (Dahlander et al. 2016). Given that attention is a fixed resource and not infinitely elastic, small nascent ventures tend to have less opportunities to search for external partners. Individual entrepreneurs can simply not scale up as larger ventures can so that "lone entrepreneurs" (Klotz et al. 2014), which are neither equipped with co-founders nor employees, have a finite search time (Dahlander et al. 2016). We therefore expect that nascent ventures with limited resources in terms of their founders have hardly any opportunities to pursue pathways during which linkages to external partners are formed, including both market- and researchoriented linkages, whereas firms with larger founder teams have more resources to build up either type of linkages:

Hypothesis 1: During their new product development process, nascent ventures with more founders are less likely than founder-scarce ventures to pursue a path where products are solely developed in- 
house and more likely to pursue a path where external linkages are formed.

Assuming that the likelihood of developing external linkages increases with a larger founder team, what kind of linkage formation paths can those firms with larger teams be expected to take? The strategy literature argues that linkages are formed, because there is the strategic need to access knowledge which is not available within the firm (Alvarez and Barney 2001; Ireland et al. 2002). An important literature strand shows that firms tend to establish linkages to those partners that allow access to critical and heterogeneous resources (Alvarez and Barney 2001; Coleman 1988; Geletkanycz and Hambrick 1997; Ireland et al. 2002; Rowley et al. 2000). Hence, the access to resources owned by partners that complement a firm's in-house capabilities seems to be an important driver to pursue a linkage formation path during the new product development process (Rowley et al. 2000). In other words, linkages may provide the benefit vis-à-vis in-house development that they provide access to complementary and nonredundant knowledge and skills (Vanhaverbeke and Noorderhaven 2001).

The ability to manage such linkages is thus considered a source of competitive advantage in particular for nascent ventures (Glaister 1998; Ireland et al. 2002): The pursuit of a path where external linkages are formed may be understood as a means for the nascent venture to add complementary competences and to move more quickly into new markets. This idea has been conceptually extended to the entrepreneurship literature when scholars argue that the function of the entrepreneur is to identify missing resources: "Especially in dynamic markets, a resource-scarce SME can leverage its unique knowledge by actively configuring and reconfiguring its collaborations...." (Rosenbusch et al. 2011).

However, the resource scarcity of nascent ventures implies that entrepreneurship may be less an "intentionally orchestrated activity" (Stenholm and Renko 2016: 595), but rather a pragmatic "make-do" behavior of bricolage (Sunduramurthy et al. 2016). ${ }^{2}$ This make-do aspect of bricolage creates a bias as actions are

\footnotetext{
${ }^{2}$ While understanding, assimilating, and applying these knowledge stocks may be challenging as it may go beyond a firm's absorptive capacity (Cohen and Levinthal 1990), complementary linkages enable a firm to rapidly locate complementary knowledge and to benefit from it, reflecting that innovation requires the combined use of various types of skills and knowledge (Nelson and Winter 1982).
}

associated with the available resources (Sunduramurthy et al. 2016), and less with an optimization strategy where those resources are sought that are lacking in the ventures' knowledge stock (Desa and Basu 2013). Entrepreneurs-or, maybe better, bricoleurs - deal with new challenges less by calculating which assets may be lacking and are needed to complement the existing knowledge base. Instead, they tend to activate those resources which are inexpensively available to the entrepreneur, and which present a "workable solution" (Stenholm and Renko 2016: 609). Hence, nascent ventures tend to make use of "whatever is at hand" (Baker and Nelson 2005).

If we extend this view to "why" specific linkage formation paths are chosen, we expect that those opportunities for linkage formation are grasped which are "at hand" (Baker and Nelson 2005), meaning that they reflect the venture's existing human resource knowledge base. From a strategy perspective, we would expect that nascent ventures would choose to pursue a linkage formation path that complements researchoriented firm resources with market-oriented resources and, respectively, market-oriented firm resources with research-oriented resources. From the bricolage perspective, however, the linkage formation path is one that complements the venture's existing resources with the same type of linkages ${ }^{3}$.

Interestingly, previous research which tried to understand drivers of distinct linkage formation types have only focused on research-oriented collaborations. Market-oriented linkages which should be a core strategy to implement new knowledge have been almost fully disregarded (see for research collaborations, e.g., Haeussler et al. (2012); Chun and Mun (2012); Okamuro et al. (2011); Soh (2003)). Extending the

\footnotetext{
${ }^{3}$ Importantly, others (e.g., Lavie and Rosenkopf 2006) have argued that the organizational path dependence can lead firms to reinforce their exploration or, respectively, exploitation strategies where the previous adoptions of one linkage type (exploration and exploitation) conditions the adoption of the same type in the future. However, the concept of organizational path dependence does not seem applicable to nascent ventures: Contrary to established firms, those factors that induce organizational path dependence and potentially inertia - such as irreversible investments, managerial commitment, and employee resistance, as well as entry and exit barriers, constraints on information accessibility, and institutional legitimation (Hannan and Freeman 1984; Hannan and Freeman 1989) - are still limited in nascent ventures, because their organizational structures are in the process of being formed and, thus, rather flexible. Given that the drivers for engaging in just one type of linkage formation are therefore hardly linked to organizational path dependence, the concept of "bricolage" seems more applicable to nascent ventures.
} 
bricolage argument to the pursuit of distinct linkage formation paths of nascent ventures, we expect that exploitation-oriented nascent ventures search for workable solutions with "what is at hand," extending their knowledge base through pursuing an exploitationoriented linkage path. More specifically, Coad and Guenther (2014) find that the hiring of employees precedes the commercial exploitation phase of the new product development process. The hiring of employees does not only provide a firm with required resources to drive the exploitation of a new product, but it also provides nascent ventures with a tool to signal legitimacy to external partners (Koch et al. 2013). Considering that hiring employees often constitutes a significant investment for nascent ventures, Coad et al. (2016) argue that ventures postpone hiring employees until they expect sales to rise. Nascent ventures hiring employees are thus typically in the exploitation phase of new product development. We therefore expect that nascent ventures with more employees pursue a linkage formation path that extends their existing operational competence by adding exploitation-oriented linkages. This leads us to our second hypothesis of why exploitation-oriented linkages are chosen:

Hypothesis 2: During their new product development process, market-oriented nascent ventures are more likely than research-oriented nascent ventures to pursue a path where in-house development is combined with exploitation-oriented linkages.

Additionally, knowledge needed for new products as well as new services has become increasingly complex and distributed across various market participants (Easingwood 1986). In line with the aforementioned strategy perspective, this would imply that the identification of, and the access to, complementary knowledge sources may provide informational advantages (Chapman et al. 2018; Meyskens and Carsrud 2013; Nieto and Santamaría 2007). Applied to the pursuit of linkage development paths, one would expect that ventures developing innovative goods would pursue a path building complementary exploitation linkages in order to identify potential new markets for their innovative product (Alvarez and Barney 2001).

But in line with our argument that the resource scarcity of nascent ventures disables them to form linkages to access complementary knowledge sources, we expect that innovative nascent ventures pursue paths in line with a bricolage perspective. If this is the case, entrepreneurs will rather make use of the resources which are "at hand" (Baker and Nelson 2005: 331; see also Baker et al. 2013) and pursue a linkage formation path which extends (rather than complements) their existing exploration-oriented knowledge. This leads us to our third hypothesis:

Hypothesis 3: During their new product development process, innovative nascent ventures are more likely than non-innovative nascent ventures to pursue a path where in-house development is combined with exploration-oriented linkages.

\section{Methods and data}

\subsection{The data: sample and operationalization}

To test the above propositions and hypotheses, we draw our data from a unique firm-level dataset entitled "perfect timing database," which contains overall 870 nascent ventures and their start-up processes. More concretely, founders of these ventures were interviewed about the activities they undertook between the start and end of venture creation. The interviews were carried out with founders in two waves between 2011 and 2018, based on computer-assisted telephone interviews by an international research team located in Utrecht (the Netherlands), New York (the USA), Germany (Düsseldorf and Cologne), London (the UK), and Palermo (Italy). In order to capture possible variations in venture creation processes, the population interviewed includes ventures of all legal forms (excluding sole proprietorship) that were registered between 2004 and 2014 in the information and communication technology (ICT) and renewable energy (RE) industries in Germany, Italy, the USA, the Netherlands, and the UK. From this population, founders were randomly selected and invited to participate in an interview about the venture creation process of their venture until a representative sample of 870 cases had been obtained. Out of these 870 cases, we isolated those 370 ventures that indicated to have developed a new product as part of their venture creation process. All further analyses are based on these 370 ventures.

The data was collected with an explicit focus on the sequencing of venture creation activities, including 
external linkage formation activities, which allows us to study pathways of linkage formation in ventures' new product development processes. Given that the dataset covers the initial phase of the venture creation process, it provides dynamic insights into the activities of nascent ventures. More concretely, the venture creation processes covered in the database begin with the moment when a founder first discussed the idea to set up the respective venture with another person and it ends at the moment in which the venture in question became profitable, was merged, was acquired, or went bankrupt. If none of these events occurred until the date of the interview, the process of venture creation was categorized as ongoing and recorded up to a maximum duration of 84 months. The shortest venture creation process included in the below analyses thus is 3 months, the longest one is 84 months.

The new product development process, which is at the core of our study, constitutes a sub-process within the overall venture creation process. It covers the period from the beginning of the in-house product development activities until the moment of the last registered product development activity. With regard to the linkage formation activities undertaken during this new product development process, the dataset reports which activities were undertaken to develop the product on a monthly basis.

Given that the data collected relies on the founders' memory about activities they undertook in the past, there is a risk of recall bias, especially in longer venture creation processes. Founders may simply not remember well which and when they undertook activities. This, in turn, would negatively affect the reliability of the data collected. To address the risk of recall bias, the questionnaire was constructed in such a way that the founders were guided from major (formal) events (such as the registration of their venture) to minor events (such as the date when they entered an industry association). The major events were taken as anchor points to reconstruct the moments of minor events. Importantly, the interview processes showed that giving birth to a venture is similar to giving birth to a child: The core moments are never forgotten and/or can always be reconstructed. Yet, to cross-check the data validity, the interviewers carried out follow-up interviews with co-founders of the same venture, as well as with the same founder 9-48 months after the first interview. These second interviews demonstrated very high interrater agreements across the dataset.
The use of this unique dataset has three important advantages: First, to the best of our knowledge, this survey is currently the most detailed one on new product development processes in nascent ventures. Given that it provides evidence on a monthly basis, it provides sound dynamic insights into the product development and linkage formation paths of nascent ventures and the drivers of these paths. Second, thanks to the sophisticated interview techniques applied, the reliability of the data reported is high, as has been demonstrated through second interviews with both founders and co-founders. Third, thanks to the random interview sampling, the ventures surveyed are — within the IT and renewable energy industries - representative in terms of their legal forms, geographic coverage, and the novelty of their products.

\subsection{Measures}

\subsubsection{Dependent variable}

The dependent variable (linkage formation path) refers to the process with which a venture develops its new product in-house or through research and market linkages. Hence, we differentiate between two linkage choices, namely, research and/or market linkages (see also Shi and Prescott 2011: 1050). Throughout a path, several linkage formation activities (states) can be undertaken. As outlined above, research-oriented linkages refer to exploration-oriented collaborations with external actors, while market-oriented linkages refer to exploitation-oriented collaborations. Of course, a venture can simultaneously develop its product in-house and through external linkages. Therefore, we distinguish between three basic activities (states) of new product development (in-house (ID), research linkages (RL), and market linkages (ML) ${ }^{4}$ and account for possible combinations thereof, resulting into seven possible activity states that can occur in a venture's new product development process (see Table 1). This distinction allows us to differentiate not only between different combinations of linkages but also to differentiate between parallel and sequential paths of linkage formation activities. Given that the data about these in-house development and linkage activities are provided on a

\footnotetext{
${ }^{4}$ ID (in-house development) therefore refers to the monthly activity of a venture. This needs to be differentiated from the cluster where inhouse development is dominating (IH).
} 
monthly basis, we can run fine-grained sequence analyses of how new product development processes unfold in nascent ventures over time.

We operationalize linkage formation as follows: A venture's membership in a $R \& D$ project with one or more external partners is taken as a proxy for the formation of a research linkage or an exploration-oriented linkage. In our survey, entrepreneurs explained their motivation to enter such a research linkage with the access to new technological knowledge. Table 2 provides a detailed overview of ventures' motivation to join an $R \& D$ project. In turn, a venture's membership in an industry association or consortium is taken as a proxy for the formation of a market linkage as entrepreneurs indicated that entering the association was chiefly motivated by their need for exploiting related knowledge, such as obtaining information about market participants (see Table 3). Whenever a nascent venture formed either a research or a market linkage, we determined the month and year of the linkage formation start as well as the month and year of the formation end.

This classification allows us, for each nascent venture, to develop fine-grained sequences of linkage formation paths consisting of the activities that were undertaken on a monthly basis. Table 4 provides an example. In this example, the linkage formation path chosen for new product development takes place over a period of 9 months, which corresponds to the period from the beginning of product development to the moment when the venture creation process was completed. During the first 2 months, the venture develops the new product inhouse. In month 3 , the venture starts to jointly develop the product with an external partner, say, a research lab, and thus forms a research linkage. The research linkage is maintained until month 5 . In month 5 , the venture additionally creates a market linkage by entering an industry association to assure the product's market fit. In month 8, it enters another research linkage to improve the product. The row "sequence of activities (states)" aggregates the linkage formation activities for every
Table 2 Motives to enter R\&D Collaboration (research linkages)

\begin{tabular}{lll}
\hline Type of linkage & $N$ & In \% \\
\hline Development & 104 & $75.4 \%$ \\
Research and development & 13 & $9.4 \%$ \\
Research & 14 & $10.1 \%$ \\
Other & 7 & $5.1 \%$ \\
Total & 138 & $100 \%$ \\
\hline
\end{tabular}

month to a path of linkage formation activities during the new product development process. In a later step, these linkage formation paths are aggregated and clustered (see Table 4).

\subsubsection{Independent variables}

In line with the above hypotheses, the key independent variables studied include (H1) the human resources of nascent ventures with regard to its founder team, (H2) the number of employees (as an indicator of the market orientation of the venture), and (H3) a product's novelty (as an indicator of the venture's research orientation).

The variable number of founders (H1) describes the resource endowment of a venture in terms of founders. It is measured 3 months after the start of the product development process. Given that the nascent ventures of our sample rarely have more than 5 founders, this variable distinguishes between $1,2,3,4$, and 5 or more founders.

The variable number of employees $(\mathrm{H} 2)$ indicates the extent of market orientation of a nascent venture. Akin to the number of founders, the number of employees was determined 3 months after the venture started its first product development activity. Importantly, the two variables do conceptually and operationally not overlap as we clearly distinguished between founders and employees during the data collection process on the basis of the compensation they received. Collaborators who received a regular salary were classified as employees, whereas collaborators who received shares (or no

Table 1 Linkage formation activities in new product development processes

\begin{tabular}{lll}
\hline In-house development & External linkages & In-house development and external linkages \\
\hline In-house development (ID) & Market linkage (ML) & ID\&ML \\
& & ID\&RL \\
& Research linkage (RL) & ML \& RL \\
& & ID\&ML\&RL \\
\hline
\end{tabular}


Table 3 Motives to enter industry associations (market linkages)

\begin{tabular}{lll}
\hline Type of linkage & $\mathrm{N}$ & In \% \\
\hline Market & 105 & $70.0 \%$ \\
Market and research & 14 & $9.3 \%$ \\
Other business contacts & 31 & $20.6 \%$ \\
Total & 150 & $100 \%$ \\
\hline
\end{tabular}

compensation) in return for their contributions to venture creation were classified as founders. Accordingly, each person who assisted in venture creation could do so either in the form of a founder or in the form of an employee.

The variable product novelty $(\mathrm{H} 3)$ refers to a product's innovativeness relative to those of other firms and indicates the extent of research orientation of a nascent venture. To be more specific, a product's novelty has been defined in three steps. First, the founder was asked how novel her product idea was when the venture was founded. Second, each interviewer was trained in the industry's main innovative products and was thus able to compare a product's novelty across the industry-a skill which was refined with each interview conducted. Interviewers were thus able to cross-check the founder's answer by comparing the product's innovativeness with those of other ventures. In the third step, the three project coordinators (familiar with the industries' main innovations thanks to their longstanding experience in data cleaning), again cross-checked the product's novelty, indicated against a classification scheme that was developed while cleaning the entire dataset. In both step two and step three, the interviewer and the data cleaner relied on the information provided by the founder as well as on online information about the venture's business idea. While subjectivity is a typical problem in survey analysis, this three-step process made it possible to minimize the over-estimation bias that typically occurs when founders self-report the level of their business' innovativeness. The product's novelty was measured as imitation (0), incremental innovation (1), and radical innovation (2). Innovative ventures are thus defined as those ventures which have developed incrementally or radically innovative products.

We control for further venture characteristics that might influence the pursuit of specific linkage formation paths. Even though our overall sample is rather large, the application of clustering methods by definition creates smaller sub-samples. Given its fine-grained nature, our dataset is especially prone to produce small and very specific clusters. As a consequence of the small $\mathrm{N}$ in some clusters, we limit the number of control variables to avoid overfitting the regression models and, thus, degrees-of-freedom problems.

We include industry as a control, because industries are structurally different and induce ventures to pursue different business models. Different industries may therefore require distinct organizational structures (Sine et al. 2006) and encourage the pursuit of different linkage formation paths. We group ventures into ICT (0) and renewable energy (1) ventures. In those few cases where ventures had more than one industry affiliation, we classified their main activity field as the relevant industry affiliation.

As a second control variable, we include that the type of good a venture produces into our models in order to distinguish between ventures developing a tangible product (2), a non-tangible service (0), or a mixture thereof (1). The reason for including this control is that the development of tangible products may require different linkage formation approaches than the development of non-tangible services.

Third, we control for the institutional setting, or the variety of capitalism $(\mathrm{VoC})$, in which a venture operates. The VoC literature (Hall and Soskice 2001) assumes that economic interaction is organized differently

Table 4 Example of an external linkage formation path in a new product development process

\begin{tabular}{|c|c|c|c|c|c|c|c|c|c|}
\hline \multirow[t]{2}{*}{ Activity } & \multicolumn{9}{|c|}{ Month } \\
\hline & 1 & 2 & 3 & 4 & 5 & 6 & 7 & 8 & 9 \\
\hline Internal or in-house development & ID & ID & ID & ID & ID & ID & & & \\
\hline \multirow[t]{2}{*}{ External development } & & & $\mathrm{RL}$ & $\mathrm{RL}$ & $\mathrm{RL}$ & & & RL & RL \\
\hline & & & & & ML & ML & ML & ML & \\
\hline Sequence of activities (states) or "path" & ID & ID & ID\&RL & ID\&RL & ID\&RL\&ML & ID\&ML & ML & RL\&ML & RL \\
\hline
\end{tabular}


between countries which, in turn, is shaping the strategies of economic actors within a country through a distinct set of institutions. The VoC literature has identified distinct institutional constellations, among which liberal market economies (LMEs), coordinated market economies (CMEs), and mixed market economies (MMEs) constitute the most prominent archetypes.

With regard to linkage formation with external partners, the legal system of an economy is said to influence the choices made by companies. According to the $\mathrm{VoC}$ literature (Tate 2001; Teubner 2001), the reason for this is that the predictability of the outcome of lawsuits between collaboration partners is influenced by the country's legal system. Against this backdrop, the code-based legal system of CMEs yields the highest degree of predictability which, in turn, is said to foster the formation of external linkages. Contrary to that, the case-based legal system of LMEs leads to less predictability - as is the case in MMEs where long delays as a result of a dysfunctional legal system induce high levels of unpredictability (Tate 2001; Teubner 2001). As a result, nascent ventures in LMEs and MMEs might form less external linkages and, thus, pursue different linkage formation paths than their counterparts in CMEs.

Table 5 provides a descriptive overview of the independent and control variables included in our analyses.

\subsection{Econometric model and estimation method}

To identify, first, the most frequently pursued linkage formation paths and, second, the circumstances that lead firms to follow one rather than another path, we proceed in two steps. (1) First, we use sequence analyses (more concretely optimal matching techniques) to detect the type and order of linkage formation activities during the product development process, and (2) second we identify the circumstances with the use of binary logistic regression analyses. While we describe both methodological approaches below, we focus on optimal matching techniques because this method-which was also used to decode the human genome - is still novel to, and thus less well known in, business and management studies.

\subsubsection{Optimal matching techniques}

Sequence analyses based on optimal matching techniques make it possible to identify the types and order,
Table 5 Descriptive statistics

\begin{tabular}{|c|c|c|c|}
\hline Variable & Value & $N$ & In $\%$ \\
\hline \multirow[t]{3}{*}{ Product novelty } & Imitative (0) & 97 & $26.22 \%$ \\
\hline & Incremental (1) & 202 & $54.59 \%$ \\
\hline & Radical (2) & 71 & $19.19 \%$ \\
\hline \multirow[t]{6}{*}{ Number of founders } & 0 & 11 & $2.97 \%$ \\
\hline & 1 & 104 & $28.11 \%$ \\
\hline & 2 & 119 & $32.16 \%$ \\
\hline & 3 & 66 & $17.84 \%$ \\
\hline & 4 & 32 & $8.65 \%$ \\
\hline & $5+$ & 38 & $10.27 \%$ \\
\hline \multirow[t]{6}{*}{ Number employees } & 0 & 211 & $57.03 \%$ \\
\hline & 1 & 50 & $13.51 \%$ \\
\hline & 2 & 35 & $9.46 \%$ \\
\hline & 3 & 22 & $5.95 \%$ \\
\hline & 4 & 12 & $3.24 \%$ \\
\hline & $5+$ & 40 & $10.81 \%$ \\
\hline \multirow[t]{2}{*}{ Industry } & $\operatorname{ICT}(0)$ & 255 & $68.92 \%$ \\
\hline & Renewable energy (1) & 115 & $31.08 \%$ \\
\hline \multirow[t]{3}{*}{ Type of good } & Service $(0)$ & 78 & $21.08 \%$ \\
\hline & Mix (1) & 230 & $62.16 \%$ \\
\hline & Product (2) & 62 & $16.76 \%$ \\
\hline \multirow[t]{3}{*}{$\mathrm{VoC}$} & CME (1) & 175 & $47.29 \%$ \\
\hline & MME (2) & 45 & $12.16 \%$ \\
\hline & LME (3) & 150 & $40.54 \%$ \\
\hline
\end{tabular}

as well as the timing, of activities (also called states) occurring during a process - in our case, of linkage formation activities occurring during the product development process. Optimal matching (OM) techniques were originally developed in computer sciences and then applied in natural sciences to analyze for example DNA sequences and later used in sociology - in particular for analyses of career paths (Biemann et al. 2012; Dlouhy and Biemann 2015). Like a career, the new product development process is made up of single states or activities (namely, in-house development, and development through research and/or market linkages), which together form a sequence (see Table 4). This sequence (or path) is analyzed in a similar way as a DNA sequence, with the linkage formation states of product development process replacing the nucleotides of the DNA as the sequence elements. OM techniques can thus identify the most frequently pursued paths towards linkage formation during the new product development process, by matching the type and timing of 
in-house development and linkage formation activities. To this end, the $\mathrm{OM}$ algorithm measures the distance between paths (or: sequences of states) and is subsequently paired with cluster analyses in order to identify "clean" clusters (Halpin 2010). Compared to other methods like traditional cluster analyses, OM has been found to deliver superior results in identifying paths in sequence data because OM provides "cleaner" clusters (Biemann and Datta 2014).

In the context of new venture creation, the first detailed OM application focuses on team formation processes (Held et al. 2018). In a more general study on venture creation processes, Gordon (2012) uses OM techniques to sequence gestation activities. Given that more wide-ranging developments and applications of OM algorithms only occurred after the year 2000, OM can still be considered a fairly young method. Nevertheless, a standard way of running sequence analyses, based on $\mathrm{OM}$ techniques, has crystallized, which we here follow (Biemann and Datta 2014). It includes four steps.

Step 1: Coding the data. The first step consists in reporting the linkage formation path of each venture on a monthly basis. This means that a sequence of linkage formation states, depicting each venture's linkage formation path, needs to be created for each venture (for an example, see Table 2). The reported linkage formation path can vary in length for each venture as the length is a result of time that passed between the first product development activity and the end of the venture creation process.

Step 2: Define the substitution costs. In order to measure the distance between two linkage formation sequences, created in step 1, a cost needs to be assigned for replacing one state by any other state with the aim of transforming one sequence into the other. These socalled substitution costs range from 0 to an arbitrary maximum (here: 2 ) and are estimated on the basis of the relative frequency of transitions between two states within the entire dataset. The rationale underlying these approaches is that the more often a transition occurs between a pair of states, the more similar the states are (Biemann and Datta 2014). Based on this transition frequency between any two states, a so-called substitution cost matrix is determined (Held et al. 2018).
Step 3: Calculating sequence similarity. Based on these substitution costs, it is then calculated how costly it is to transform each of the 370 sequences in our dataset into any of the other 369 sequences. The cost of transforming one sequence into the other expresses their respective distance to one another. To determine the distance of two sequences that differ in length, we calculate their distance based on the length of the shorter sequence. This reflects that the shorter linkage formation path is unknown beyond the period observed and should thus not influence the distance measure. This novel solution was introduced in Held et al. (2018) and addresses an often voiced concern of using OM for analyzing sequences in social science that vary greatly in length (Aisenbrey and Fasang 2010).

Furthermore, we normalize the respective values of sequence difference by dividing them by the length of the shorter of the two sequences in order to maintain a comparable difference measure across sequence pairs. This results in a matrix which reports the distances between each sequence pair.

Step 4: Perform a cluster analysis. In a final step, these linkage formation paths are clustered on the basis of their respective distances to one another. Consequently, each cluster obtained encompasses those paths that are particularly similar to each other, and distant to the paths of other clusters. Accordingly, each cluster represents one of the most frequent and, thus, typical linkage formation paths during new product development. We run the cluster analysis based on the Ward's minimum variance method, which has been shown to consistently produce the most accurate sequence clustering within the framework of OM analyses (Dlouhy and Biemann 2015).

We use a combination of various partition quality measurements, namely, the weighted average silhouette width (ASWw), $R^{2}$, point biserial correlation (PBC), and Hubert's $\mathrm{C}(\mathrm{HC})$, to determine the optimal clustering solution among all solutions between one and twenty clusters. These measures indicate how similar sequences are within one cluster and how different they are between clusters. Consequently, we calculated these indicators for one, two, three, etc., up to twenty clusters in order to determine their goodness of fit. In this way, we could determine for which cluster number the goodness of fit is maximized. In doing so, we could exclude those cluster solutions which either did not yield distinct approaches, because they clustered together too 
different sequences, or which spread out sequences over too many similar clusters. In the end, each cluster can be pictured with a most representative sequence of states (marked with "rep." in our result Fig. 1).

\subsubsection{Estimations based on binary logistic regressions}

Once optimal matching analyses have allowed us to identify the most common paths (i.e., the types and order) of linkage formation during the new product development process, we want to understand "what factors cause the different sequences observed" (Van de Ven and Engleman 2004, p. 355), i.e., what circumstances drive ventures to pursue one rather than the other paths. We use binary logistic regression models in order to identify the conditions that lead nascent ventures to pursue a distinct path (dependent variable). Given that we want to estimate the probability of choosing one path against all other

Cluster 1: In-house Developers (IH)

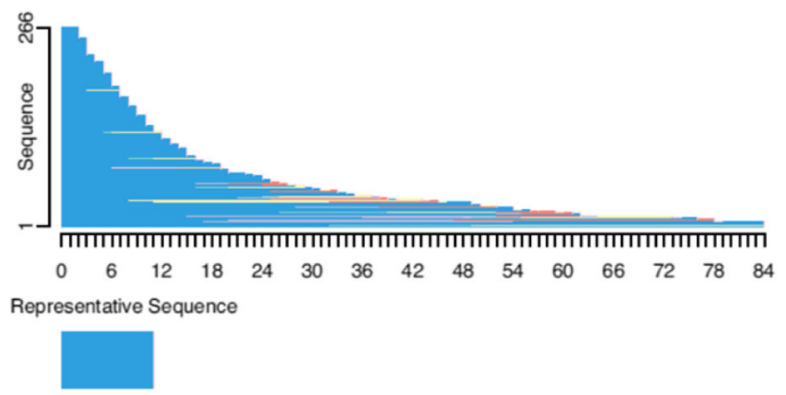

Cluster 3: In-house \& Market Linkage Developers - Sequential (IH / ML)

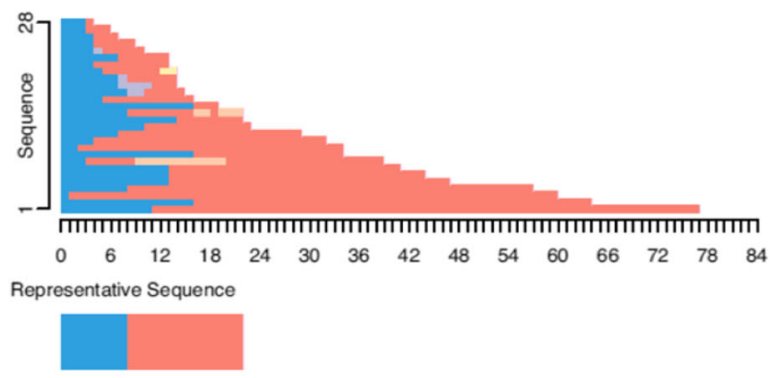

$\square$ Internal Development (ID)

$\square$ Research Linkage (RL)

$\square$ ID \& RL

$\square$ Market Linkage (ML)

$\square$ ID \& ML

$\square R L \& M L$

$\square$ ID \& RL \& ML

Fig. 1 Patterns of linkage formation activities in product development processes. Cluster 1: In-house developers (IH). Cluster 2: In-house and research linkage developers - parallel (IH and RL). paths, i.e., of pursuing one path compared to all other options, we use binary logistic rather than multinomial logistic regression analyses in order to understand what drives nascent ventures to pursue this one compared to all other pathways. This approach is also in line with a recent publication using sequence analysis which investigates team formation processes (Held et al. 2018).

In testing our hypotheses, we research into how a venture's human resource scarcity (in terms of number of founders), its market orientation (in terms of number of employees), and its research orientation (in terms of product/service novelty) as independent variables are associated with distinct pathways of linkage formation during new product development as the dependent variable. We furthermore control for the venture's industry, its country's legal system, and whether it develops a service or rather a tangible good.

Cluster 2: In-house \& Research Linkage Developers - Parallel (IH \& RL)

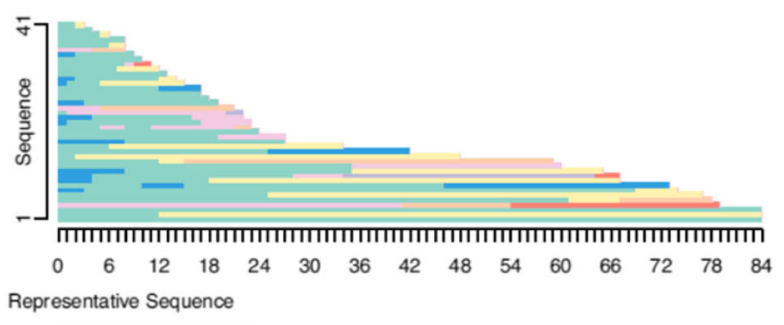

Cluster 4: In-house \& Market Linkage Developers - Parallel (IH \& ML)

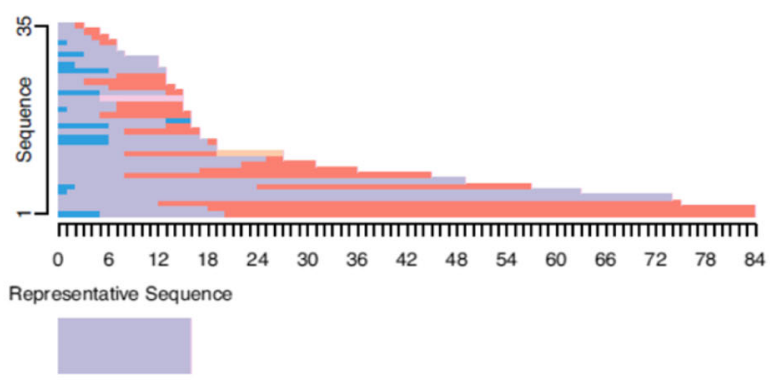

Cluster 3: In-house and market linkage developers - sequential (IH/ML). Cluster 4: In-house and market linkage developers — parallel (IH and ML) 
We fit the following model for each cluster to obtain the estimates:

$\ln \left(\frac{p_{i}}{1-p_{i}}\right)=\beta_{0}+\beta_{1}$ Novelty $_{i}+\beta_{2}$ Founders $+\beta_{3}$ Employees $+\boldsymbol{\beta}^{\prime} \boldsymbol{x}_{i}$

where $p_{i}$ denotes the probability that venture $i$ belongs to the cluster rather than to any of the other clusters; $\beta_{0}$ is the cluster's intercept; $\beta_{1}, \beta_{2}$, and $\beta_{3}$ the estimated coefficients for our independent variables; $\boldsymbol{\beta}$ is the vector of coefficients for the control variables; and $\boldsymbol{x}_{i}$ is the vector of control variables.

\section{Results}

4.1 Linkage formation paths of nascent ventures in new product development

In order to test our propositions, we explore, in the first part of our analysis, the paths of linkage formation activities during the new product development processes of nascent ventures. To this end, the algorithm "optimally matches" sequences on a monthly basis and allows us to gain a fine-grained picture of the precise linkage paths during the new product development process. These optimal matching analyses reveal four clusters and, thus, four distinct sequences or linkage formation paths during product development, namely, (1) inhouse development only (IH), (2) in-house development in parallel with research linkages (IH \& RL), (3) inhouse development sequentially followed by market linkages (IH/ML), and (4) in-house development in parallel with market linkages (IH \& ML). This solution combines the partition quality measurements better than any other considered solution $\left(\mathrm{ASWw}=0.69 ; R^{2}=\right.$ 0.73; $\mathrm{PBC}=0.77 ; \mathrm{HC}=0.09$ ).

Figure 1 provides an overview of these four clusters of most common paths, whereby the $x$-axis of each cluster is a timeline on the basis of months, while the $y$-axis reports the product development process (sequences of states) pursued by each venture within that cluster. As illustrated in Section 3.2.1, each path consists of several development activities. To distinguish these activities (that we traced on a monthly basis) from the entire path, we use different abbreviations, in particular to distinguish the (monthly) internal development activity (ID; see Table 4) from the in-house development path of cluster 1 (IH). Accordingly, the most representative path of cluster 1 (IH) includes 266 individual paths, while the most representative sequence of cluster 2 (IH \& RL) includes 41 individual paths. The clusters characterized by market linkages are smaller with 28 individual paths in cluster $3(\mathrm{IH} / \mathrm{ML})$ and 35 in cluster 4 (IH \& ML). Importantly, the most representative path or sequence is reported by the bar underneath each cluster. ${ }^{5}$

In alignment with our first proposition, it is noteworthy that the, by far, most commonly pursued path consists in in-house product development (cluster $1(\mathrm{IH})$ ). Overall, 266 (and thus $71.9 \%$ of) nascent ventures within our sample pursue this path to develop their new product. As illustrated by the most "representative sequence" bar (below each cluster), these ventures refrain from forming any external linkages. Among all four approaches to new product development, pure inhouse development is the, by far, shortest one as ventures take on average 10 months to develop a functional prototype.

In alignment with our second proposition, and contrary to previous findings (Burgers et al. 2008; Lee et al. 2010; Rothaermel and Deeds 2004), hardly any nascent venture develops its product by building first research and then market linkages (Rothaermel and Deeds 2004) or by combining exploration- and exploitation-oriented linkages simultaneously (Shi and Prescott 2011). Instead, nascent ventures choose only one linkage, i.e., either market- or research-oriented linkages. While we hereby find empirical support for Proposition 2, we also see that there are different ways in which nascent ventures combine in-house development with just one linkage type, namely, in parallel or sequentially. Accordingly, clusters 2-4 show that if nascent ventures do not develop their products exclusively in-house, virtually all nascent ventures form either external research linkages (cluster 2 (IH \& RL)) or external market linkages either after completing, or

\footnotetext{
${ }^{5}$ Given that sequence analysis condenses the order of individual sequences into most representative sequences, the latter may not be characterized by changes in activities even though most representative sequences are chiefly informed by the order of activities within individual sequences. As can be seen from Figure 1, most representative sequences may therefore look static, even though they represent a high order variety within individual linkage formation processes.
} 
in parallel to, in-house product development (clusters 3 (IH/ML) and 4 (IH \& ML)).

$>$ More concretely, nascent ventures in the smaller cluster 2 (IH \& RL, $n=41 ; 11.08 \%$ of the sample) run in-house development in parallel to entering research linkages throughout the product development process lasting about 22 months. Ventures in cluster $4(n=35$; $9.5 \%$ of the sample) enter into market (rather than research) linkages in parallel to developing their new product in-house. Interestingly, this parallel development lasts longer for the combination in-house and research linkages (namely, on average 22 months) than for the combination in-house and market linkages (on average 16 months). Ventures in cluster 3 (IH/ML; $n=$ $28 ; 7.6 \%$ of the sample) also combine in-house development with just one linkage formation type (namely, market linkages) but in a sequential way (rather than in parallel). Accordingly, they begin the process of developing their new product in-house but start creating market linkages, on average, in month 8 . We can therefore observe a clear two-step sequence of first developing the product in-house and then ensuring its market fit. Interestingly, parallel in-house and market linkage development enables nascent ventures to complete product development activities after 16 months and, thus, takes less time than sequential in-house and market linkage development, where product development activities go on until month 22 .

In sum, and in line with Propositions 1 and 2, we find that nascent ventures have a clear preference for either developing their products in-house or combining in-house development with just one linkage type. While we thus find support for the argument of resource scarcity, our finding also challenges the strategy literature which, to date, mostly argues that ventures strategically combine both research and market linkages in order to develop their new products.

4.2 Drivers s of linkage paths of nascent ventures in new product development processes

Having identified how the most frequent linkage formation paths during new product development look like, we want to understand what factors drive the pursuit of each process: Why do nascent ventures pursue one rather than the other paths? ${ }^{6}$ To answer this question, we follow Held et al. (2018) and use binary logistic regressions to compare the characteristics of ventures in one cluster with those of the other clusters in order to determine in how far cluster membership is correlated with particular venture characteristics, namely, human resource scarcity (in terms of founders), and a venture's market orientation (in terms of employees), and research orientation (in terms of product novelty). Table 6 provides an overview of the results obtained, whereby coefficients above 1.000 indicate a positive relationship, whereas coefficients below 1.000 indicate a negative relationship.

Our first hypothesis (H1) predicts that nascent ventures which are constrained in their human resources are less likely to form external linkages. The statistical evidence clearly indicates that the results obtained are not statistically significant, which implies that $\mathrm{H} 1$ needs to be rejected. While this result means that the number of a venture's founders does not influence the linkage formation path chosen in a statistically significant way, it is still noteworthy - particularly in view of the rather limited number of cases for clusters 2-4-that the directions of our findings are largely in line with $\mathrm{H} 1$ : With the exception of founder-scarce ventures engaging in market linkages next to in-house development (IH \& ML; $\operatorname{Exp} \beta=.854 ; p>.1)$, the coefficients indicate that resource scarce ventures with small founder teams tend to develop in-house (IH; $\operatorname{Exp} \beta=.939 ; p>.1)$, i.e., refrain from building up any external linkages during the new product development process, while more resource-rich ventures form research (IH \& RL; Exp $\beta=1.181 ; p>.1)$ and, respectively, market linkages (IH/ML; $\operatorname{Exp} \beta=1.191 ; p>.1$ ). Thereby, the coefficients are larger for the models predicting that founder-rich ventures choose a path with external linkages than for the model predicting that founder poor ventures choose exclusive internal product

\footnotetext{
${ }^{6}$ Contrary to event-history (or survival) analyses, regression analyses used in combination with sequence analyses relate independent variables to the entire processes investigated, not to changes within these processes.
} 
Table 6 Drivers of linkage formation paths during new product development processes (binary logistic regressions)

\begin{tabular}{|c|c|c|c|c|}
\hline \multirow[t]{2}{*}{ Variable } & \multicolumn{4}{|c|}{ New product development process $(\operatorname{Exp} \beta)$} \\
\hline & $\mathrm{IH}$ & IH \& RL (parallel) & IH/ML (sequentiel) & IH \& ML (parallel) \\
\hline Number founders & .939 & 1.181 & 1.191 & .854 \\
\hline Number employees & $.866^{* *}$ & .936 & $1.273 * *$ & $1.199 *$ \\
\hline \multicolumn{5}{|l|}{ Degree of novelty } \\
\hline - Incremental & $.387 * *$ & $25.719 * * *$ & 1.281 & $.218^{*}$ \\
\hline - Radical & $.517 * *$ & $9.365 * * *$ & .747 & 1.232 \\
\hline Renewable energy ind. & $.352 * * *$ & $4.076 * * *$ & 1.625 & 1.851 \\
\hline \multicolumn{5}{|l|}{ Type of good } \\
\hline - Mix & 1.283 & 1.853 & $.164 * * *$ & 2.441 \\
\hline - Product & 1.490 & 1.428 & $.201 * *$ & 2.360 \\
\hline \multicolumn{5}{|l|}{ VoC } \\
\hline - LME & .994 & $.437 * *$ & 1.632 & 1.385 \\
\hline - MME & .921 & .733 & .818 & 1.932 \\
\hline Intercept & $7.269 * * *$ & .005 & $.093 * * *$ & $.037 * * *$ \\
\hline Observations in cluster & 266 & 41 & 28 & 35 \\
\hline Observations in analysis & 370 & 370 & 370 & 370 \\
\hline$R^{2}$ & .103 & .219 & .146 & .097 \\
\hline
\end{tabular}

$* * * p<.01, * * p<.05, * p<.1$

development. Albeit statistically insignificant, this lends some - admittedly very tentative - support to the idea that the human resource scarcity of nascent ventures might forecloses the opportunity to form external linkages.

The second hypothesis (H2) which predicts that market-oriented nascent ventures, measured by an increase of employees, are likely to combine inhouse development with external market linkages, and hence refrain from complementary research linkages, is supported by strong effects. The more market-oriented nascent ventures are in terms of their employees, the more likely ventures are to form external market linkages. Market linkages are pursued either in parallel to in-house product development (IH \& ML; $\operatorname{Exp} \beta=1.199 ; p<.1)$ or sequentially after in-house development (IH/ML; $\operatorname{Exp} \beta=1.273 ; p<.05)$. Taken together, we find strong empirical support for hypothesis 2 .

In hypothesis $3(\mathrm{H} 3)$, we predicted that researchoriented, i.e., innovative ventures are more likely to form research linkages and hence make use out of what is "at hand"- to put it in the hands of the bricolage approach. Overall, we find strong empirical support for this hypothesis. Innovative ventures are highly unlikely to develop new products exclusively in-house, which is true for both incrementally (IH; $\operatorname{Exp} \beta=.387$; $p<.05$ ) and radically innovative ventures (IH; Exp $\beta=.517 ; \mathrm{p}<.05)$. Instead, both incrementally innovative ventures (IH \& RL; $\operatorname{Exp} \beta=25.719 ; p<.01)$ and radically innovative ventures have a tendency to form research linkages (IH \& RL; $\operatorname{Exp} \beta=9.365 ; p<.01$ ). In contrast, market-, i.e., exploitation-oriented linkages do not play a significant role for the development of innovative products. In additional support of $\mathrm{H} 3$, incrementally innovative ventures even show a significant tendency not to form market linkages after in-house development (IH \& ML; Exp $\beta=.218 ; p<.10$ ). Together with their particularly high coefficients (IH; Exp $\beta=.387 ; p<.05$; IH \& RL; Exp $\beta=25.719 ; p<.01$ ), this suggests that incrementally innovative ventures show an even stronger tendency than radically innovative ventures to engage in exploration rather than exploitation linkages. While this finding is noteworthy, our interpretation thereof can only be speculative: Given that the technological improvements of incrementally innovative ventures are more predictable, they can be better codified. This might make it easier for incrementally innovative ventures to identify opportune research linages beyond their in-house knowledge base. 
Not surprisingly, the control variables also influence which approach to new product development is chosen. We find that nascent ventures developing pure services are significantly more likely than pure product developers, or ventures developing products with a service component, to first develop their new service exclusively in-house before forming market linkages (IH/ML; $\operatorname{Exp} \beta=.201 ; p<.05)$. In addition, we find that the linkage formation activities of nascent ventures vary depending on their industry affiliation. While ICT ventures are significantly more likely than renewable energy ventures to develop their new products exclusively in-house (IH; $\operatorname{Exp} \beta=.352 ; p<.01)$, they are significantly less likely to engage in any research linkages in parallel to in-house development (IH \& RL; Exp $\beta=$ $4.076 ; p<.01)$. This finding is noteworthy as it suggests that there is a sector-specific element in linkage formation activities: More technology intensive ventures (ICT) seem more in need to form external R\&D collaborations than less technology intensive ventures (renewable energy). Concerning the institutional framework of ventures, we find - in line with the expectations of the VoC literature - that a research linkage heavy approach to new product development is less than half as likely to occur in LMEs than in CMEs (IH \& RL; $\operatorname{Exp} \beta=.437$; $p<.05)$.

\subsection{Alternative explanations of pathway choices}

One remaining open question is whether the relationship between market-oriented and research-oriented nascent ventures and their respective choices of exploitation versus exploration linkages can be identified as a causal effect. As with virtually all correlational research, there may be a concern that the relationship detected could be inflated due to an endogeneity problem, in particular the self-selection of exploitation-oriented strategies by market-oriented firms and of exploration-oriented strategies by research-oriented ventures. While we cannot fully exclude endogeneity, and although our data does not allow for a rigorous robustness check, we are confident that the direction of causality runs from market orientation and, respectively, research orientation towards the related linkage choice.

To illustrate this reasoning, we first focus on the link between market-oriented nascent ventures (with more employees) and their choice of exploitationoriented linkages. A reverse causality would mean that ventures with exploitation-oriented linkages are more likely to have a higher number of employees. In this regard, it is however important to note that the timing of our survey data allows the conclusion that firms with more employees tend to choose exploitation-oriented linkages (and not the other way around): When we carried out our survey, the founders indicated the number of employees at the start of venture creation. As demonstrated by Fig. 1 , linkages are created only later in the process of venture creation. This means that the structure of our dataset - employees have been hired first, linkages have been formed later-naturally speaks in favor of our direction of causality.

With regard to research orientation and the choice of exploration-oriented linkages, a reverse causality would mean that nascent ventures with exploration-oriented linkages develop more innovative products. Indeed, the literature on university-industry linkages assumes that linkages to universities - the most typical form of an exploration-oriented linkage - are associated with more innovation. More concretely, Fitjar and Rodriguez-Pose (2013) show that linkages to universities are associated with radical innovation. If the causality would run from the venture's linkage formation path to its innovativeness, one would therefore expect that ventures with exploration-oriented linkages show a stronger tendency to be radically rather incrementally innovative. However, we do not observe this relationship. Our results show that the effect size in the case of incrementally innovative ventures on the choice of exploration-oriented linkages is much stronger than for radically innovative ventures.

Finally, both our argument - that there is a causal effect of market-oriented firms on their choice of exploitation-oriented linkages, and that there is a causal effect of innovative firms on the choice of explorationoriented linkages - are in line with the core argument of the resource-based view that resources enhance the firm's capabilities to undertake new initiatives (Barney 1991; Penrose 1959; Wernerfelt 1984). More concretely, the available resources allow for strategic initiatives such as linkage formation. Also, the bricolage approach supports our argument. As outlined in Sections 1 and 2, this literature assumes a causality from pre-entry resources to the choice of strategies - in our case, the choice of linkages. Lastly, the rich literature on networks also points in the same direction arguing that pre-existing relationships are tapped in early entrepreneurial stages (Hoang and Antoncic 2003). 


\section{Discussion and conclusions}

Our study of how and why nascent ventures form linkages to external partners during the new product development process allows us to make major methodological and theoretical contributions. These contributions were enabled by the use of a novel method that, to date, has hardly been used in business and management studies: sequence analyses based on optimal matching techniques. By comparing entire product development processes rather than individual data points at given moments in time, this fine-grained analysis made it possible to identify four distinct linkage formation paths in new product development processes that are typically pursued by nascent ventures, namely, (1) in-house development only, (2) in-house development in parallel with external research linkages, (3) in-house development sequentially followed by product development through external market linkages, and (4) in-house development in parallel with external market linkages. Hence, out of the myriads of possibilities that may exist, we are able to identify four distinct paths. Like Shi and Prescott (2011) who identified seven paths of alliance sequences of incumbents entering strategic alliances, we have also been able to show that nascent ventures do not arbitrarily enter linkages, but do so in a structured way by following distinct paths. Our findings thus contribute to the rare literature on sequences in linkage formation activities - in a recent review by Shi et al. (2012) (Table 3 ) on the temporal perspective of strategic alliance initiatives, only two studies which use sequences (or order) as a temporal construct have been identified. To the best of our knowledge, no prior work has analyzed the temporal perspective of nascent ventures in terms of sequences as a temporal construct. We aim to fill this gap.

More concretely, our sequence analyses show that the majority of nascent ventures refrain from linkage formation, which we attribute to their resource scarcity. While not statistically significant, the related regression analyses very tentatively indicate that less resourceconstrained ventures display a higher propensity to enter linkages. Taken together, our results lead us to argue that while external linkages substantially increase a firm's competitiveness (Hoang and Rothaermel 2010; Nieto and Santamaría 2007; Rothaermel 2001), the resource scarcity of nascent ventures seems to constitute a barrier to create these linkages. In other words, the opportunity costs of ventures, which are underequipped with human resources, seem to be higher than the gains related to external linkage formation. Albeit tentative, this finding supports earlier work of Ahuja (2000) which is, to our best knowledge, the only one that has taken the role of opportunity costs of small firms in building up linkages into account. Given the rich literature on the value that external linkages create for new ventures (Hoang and Antoncic 2003; Hoang and Rothaermel 2010; Nieto and Santamaría 2007; Rothaermel 2001), our tentative finding is important as it suggests that more research is needed to better understand the drivers hindering nascent ventures to search for external linkages.

Following the recent literature on bricolage (Welter et al. 2016; Stenholm and Renko 2016; Sunduramurthy et al. 2016), we furthermore argue that resource scarcity not only shapes a venture's tendency not to form linkages but can also explain those instances in which linkages are formed. We find that the existing knowledge base shapes which linkage formation paths are pursued: More market-oriented ventures with more employees exploit their operational competence by forming market linkages, whereas more researchoriented ventures explore their competence by adding exploration linkages. Taken together, these findings indicate that resource scarcity may drive nascent ventures to not only focus on only one type of external (research or market) linkage but also to extend the existing knowledge base instead of complementing it. These results extend the predictions of the strategy literature which has argued that linkages not only add value to the venture's product (Freitas et al. 2011; Powell et al. 1996) but also that linkages tend to complement a venture's knowledge base (Ahuja 2000; Alvarez and Barney 2001; Haeussler et al. 2012; Hoang and Antoncic 2003; Ireland et al. 2002; Meyskens and Carsrud 2013). Further research, however, is needed to better understand why, within the group of research-oriented ventures, those ventures which are incrementally innovative tend to choose more often exploration-oriented linkages than radically innovative ventures.

Our findings have implications both for the strategy literature and for managers and policymakers. If linkages (Hoang and Rothaermel 2010; Nieto and Santamaría 2007; Rothaermel 2001; Soh 2003) and strategic combinations thereof (Rothaermel and Deeds 2004; Shi and Prescott 2011) indeed contribute to greater product novelty and to better product performance, the lack of linkages and combinations thereof may be a 
barrier to growth of nascent ventures. Paradoxically, given that resources are scarce, more linkages and combinations thereof cannot be initiated by the ventures themselves. Interestingly, our findings indicate that also those ventures that take more time for their new product development processes do not leave this path, but are still constrained in their choice of linkages. Hence, the observation of Lavie and Rosenkopf (2006) that firms tend to "repair" pathdependent linkage formation over time does not seem to hold true for nascent ventures. One important implication for innovation policy is that innovation intermediaries, defined as an "agent or broker... between two or more parties" (Howells 2006, p 720), may be well advised to take the variety of linkage formation patterns into account, which might enhance the performance of nascent ventures. When supporting the formation of linkages, policies need to carefully trade off the performingenhancing nature of combined exploration- and exploitation-oriented linkages on one side and the strict resource scarcity of nascent ventures on the other side. While the former speaks in favor of combining linkages-as we know it from incumbents - the latter indicates that founders of nascent ventures may simply be overburdened by searching for, choosing, and combining linkages.

In interpreting the results of this study, certain limitations must be kept in mind. First and most importantly, the identification of paths implies that we subdivide our dataset and run regression analyses on comparatively small groups of ventures. An even larger number of cases would be desirable to statistically enable the inclusion of more independent variables into the respective regression analyses. We leave the possibility of an analysis involving larger sub-samples for future research. Second, we show that a small human resource basis reduces the opportunities of nascent ventures to form linkages. Others have argued that the causality is reverse, i.e., that size is an outcome, not a predictor for linkages (Powell et al. 1996). Indeed, our dataset does not allow us to test for causality. However, our argument follows prior research which explicitly took causality into account, concluding that a reciprocal association cannot be identified (Shan et al. 1994). That said, our results are, technically speaking, of correlational a nature so that there certainly remains a need to better understand the causal relationship between linkage formation and its underlying drivers.

Acknowledgments Earlier versions of this paper were presented at the SASE conference 2019 and the TIE/VHB conference in 2020. The authors thank the participants of these conferences. In particular, we appreciate feedback from David Donald, Koen Frenken, David Heller, Sjoerd Romme, Mark Sanders, Erik Stam, Vareska van de Vrande, Karl Wennberg, and Na Zou. The authors would also like to thank Elssy Kiradjieva for the editorial support. The authors graciously thank Leon Schjoedt and two anonymous reviewers for their tremendous insights and assistance that greatly improved the paper. Open Access funding enabled and organized by Projekt DEAL.

Funding This project has received funding from the European Union's Horizon 2020 research and innovation programme under grant agreement no. 649378. This paper reflects only the authors' views, and the agency is not responsible for any use that may be made of the information it contains.

Open Access This article is licensed under a Creative Commons Attribution 4.0 International License, which permits use, sharing, adaptation, distribution and reproduction in any medium or format, as long as you give appropriate credit to the original author(s) and the source, provide a link to the Creative Commons licence, and indicate if changes were made. The images or other third party material in this article are included in the article's Creative Commons licence, unless indicated otherwise in a credit line to the material. If material is not included in the article's Creative Commons licence and your intended use is not permitted by statutory regulation or exceeds the permitted use, you will need to obtain permission directly from the copyright holder. To view a copy of this licence, visit http://creativecommons.org/licenses/by/4.0/.

\section{References}

Ahuja, G. (2000). The duality of collaboration: Inducements and opportunities in the formation of interfirm linkages. Strategic Management Journal, 21, 317-343. https://doi.org/10.1002 /(SICI)1097-0266(200003)21:3<317::AID-SMJ90>3.0. $\mathrm{CO} ; 2-\mathrm{B}$.

Aisenbrey, S., \& Fasang, A. E. (2010). New life for old ideas: the " "second wave"" of sequence analysis bringing the " course"" back into the life course. Sociological Methods \& Research, 38, 420-462. https://doi.org/10.1177/0049124109357532.

Almeida, P., Dokko, G., \& Rosenkopf, L. (2003). Startup size and the mechanisms of external learning: increasing opportunity and decreasing ability? Research Policy, 32, 301-315. https://doi.org/10.1016/S0048-7333(02)00101-4.

Alvarez, S. A., \& Barney, J. B. (2001). How entrepreneurial firms can benefit from alliances with large partners. Academy of Management Perspectives, 15(1), 139-148. https://doi. org/10.5465/ame.2001.4251563.

Baker, T., \& Nelson, R. E. (2005). Creating something from nothing: resource construction through entrepreneurial bricolage. Administrative Science Quarterly, 50(3), 329-366. https://doi.org/10.2189/asqu.2005.50.3.329. 
Baker, T., Pollock, T., \& Sapienza, H. (2013). Winning an Unfair Game: How a Resource Constrained Player Uses Bricolage to Maneuver for Advantage in a Highly Institutionalized Field. In A. C. Corbett and J. A. Katz (Eds.), In Advances in Entrepreneurship, Firm Emergence and Growth (pp. 141). Bingley: Emerald Group Publishing Limited.

Bamford, C. E., Dean, T. J., \& McDougall, P. P. (2000). An examination of the impact of initial founding conditions and decisions upon the performance of new bank start-ups. Journal of Business Venturing, 15(3), 253-277. https://doi. org/10.1016/S0883-9026(98)00011-1.

Barney, J. (1991). Firm resources and sustained competitive advantage. Journal of Management, 17, 99-120. https://doi. org/10.1177/014920639101700108.

Biemann, T., \& Datta, D. K. (2014). Analyzing sequence data: optimal matching in management research. Organizational Research Methods, 17, 51-76. https://doi.org/10.1177 /1094428113499408.

Biemann, T., Zacher, H., \& Feldman, D. C. (2012). Career patterns: a twenty-year panel study. Journal of Vocational Behavior, 81, 159-170. https://doi.org/10.1016/j. jvb.2012.06.003.

Burgers, J. H., Van Den Bosch, F. A. J., \& Volberda, H. W. (2008). Why new business development projects fail: coping with the differences of technological versus market knowledge. Long Range Planning, 41, 55-73. https://doi. org/10.1016/J.LRP.2007.10.003.

Carayannopoulos, S., \& Auster, E. R. (2010). External knowledge sourcing in biotechnology through acquisition versus alliance: a KBV approach. Research Policy, 39, 254-267. https://doi.org/10.1016/J.RESPOL.2009.12.005.

Chapman, G., Lucena, A., \& Afcha, S. (2018). R\&D subsidies \& external collaborative breadth: differential gains and the role of collaboration experience. Research Policy, 47, 623-636. https://doi.org/10.1016/J.RESPOL.2018.01.009.

Chun, H., \& Mun, S. B. (2012). Determinants of R\&D cooperation in small and medium-sized enterprises. Small Business Economics, 39, 419-436. https://doi.org/10.1007/s11187010-9312-5.

Coad, A., \& Guenther, C. (2014). Processes of firm growth and diversification: theory and evidence. Small Business Economics, 43, 857-871. https://doi.org/10.1007/s11187014-9566-4.

Coad, A., Nielsen, K., \& Timmermans, B. (2016). My first employee: an empirical investigation. Small Business Economics. https://doi.org/10.1007/s11187-016-9748-3.

Cohen, W. M., \& Levinthal, D. A. (1990). Absorptive capacity: a new perspective on learning and innovation. Administrative Science Quarterly., 35(1), 128-152. https://doi.org/10.2307 12393553 .

Coleman, J. S. (1988). Social capital in the creation of human capital. American Journal of Sociology, 94, S95-S120 www. jstor.org/stable/2780243.

Cunha, M. P. E., Rego, A., Oliveira, P., Rosado, P., \& Habib, N. (2014). Product innovation in resource-poor environments. Journal of Product Innovation Management, 31, 202-210. https://doi.org/10.1111/jpim.12090.

Dahlander, L., O’Mahony, S., \& Gann, D. M. (2016). One foot in, one foot out: how does individuals' external search breadth affect innovation outcomes? Strategic Management Journal, 37, 280-302. https://doi.org/10.1002/smj.2342.
Desa, G., \& Basu, S. (2013). Optimization versus bricolage in global social entrepreneurship. Strategic Entrepreneurship Journal, 7, 26-49. https://doi.org/10.1002/sej.1150.

Dlouhy, K., \& Biemann, T. (2015). Optimal matching analysis in career research: a review and some best-practice recommendations. Journal of Vocational Behavior, 90, 163-173. https://doi.org/10.1016/j.jvb.2015.04.005.

Easingwood, C. J. (1986). New product development for service companies. Journal of Product Innovation Management, 3, 264-275. https://doi.org/10.1016/0737-6782(86)90005-6.

Eisenhardt, K. M., \& Schoonhoven, C. B. (1996). Resource-based view of strategic alliance formation: Strategic and social effects in entrepreneurial firms. Organization Science, 7, 136-150. https://doi.org/10.1287/orsc.7.2.136.

Fitjar, R. D., \& Rodriguez-Pose, A. (2013). Firm collaboration and modes of innovation in Norway. Research Policy, 42(1), 128-138. https://doi.org/10.1016/j.respol.2012.05.009.

Freitas, I. M. B., Clausen, T. H., Fontana, R., \& Verspagen, B. (2011). Formal and informal external linkages and firms' innovative strategies. A cross-country comparison. Journal of Evolutionary Economics, 21, 91-119. https://doi. org/10.1007/s00191-010-0188-y.

Geletkanycz, M. A., \& Hambrick, D. C. (1997). The external ties of top executives: Implications for strategic choice and performance. Administrative Science Quarterly, 42(4), 654681. https://doi.org/10.2307/2393653.

Glaister, K. W. (1998). Strategic motives for UK international alliance formation, in: international strategic management and government policy (pp. 40-77). London: Palgrave Macmillan UK. https://doi.org/10.1007/978-1-349-266463 . 4 .

Gordon, S. R. 2012. Dimensions of the venture creation process: amount, dynamics, and sequences of action in nascent entrepreneurship. Doctoral dissertation, Queensland University of Technology, Brisbane. https://eprints.qut.edu.au/58078 /1/Scott_Gordon_Thesis.pdf.

Greve, H. R. (2007). Exploration and exploitation in product innovation. Industrial and Corporate Change, 16(5), 945975. https://doi.org/10.1093/icc/dtm013.

Grilli, L., \& Murtinu, S. (2018). Selective subsidies, entrepreneurial founders' human capital, and access to R\&amp;dalliances. Research Policy, 47(10), 1945-1963. https://doi.org/10.1016 /J.RESPOL.2018.07.001.

Grilli, L., Jensen, P. H., Murtinu, S. 2014. The imprinting of founders' human capital on entrepreneurial venture growth: evidence from new technology-based firms. Melbourne institute working paper (June 11, 2014). https://doi.org/10.2139 /ssrn.2456721.

Haeussler, C., Patzelt, H., \& Zahra, S. A. (2012). Strategic alliances and product development in high technology new firms: the moderating effect of technological capabilities. Journal of Business Venturing, 27, 217-233. https://doi. org/10.1016/J.JBUSVENT.2010.10.002.

Hall, P. A., \& Soskice, D. (2001). An introduction to varieties of capitalism. In P. A. Hall \& D. Soskice (Eds.), Varieties of capitalism: the institutional foundations of comparative advantage (pp. 1-71). Oxford: Oxford University Press. https://doi.org/10.1093/0199247757.003.0001.

Halpin, B. (2010). Optimal matching analysis and life-course data: the importance of duration. Sociological Methods \& 
Research, 38, 365-388. https://doi.org/10.1177 /0049124110363590.

Hannan, M., \& Freeman, J. (1984). Structural inertia and organizational change. American Sociological Review, 49(2), 149164. https://www.jstor.org/stable/2095567.

Hannan, M., \& Freeman, J. (1989). Organizational ecology. Cambridge: Harvard University Press.

Held, L., Herrmann, A. M., \& van Mossel, A. (2018). Team formation processes in new ventures. Small Business Economics, 51, 1-24. https://doi.org/10.1007/s11187-0180010-z.

Hennart, J.-F. (1991). The transaction costs theory of joint ventures: an empirical study of Japanese subsidiaries in the United States. Management Science, 37, 483-497. https://doi.org/10.1287/mnsc.37.4.483.

Hill, S. A., \& Birkinshaw, J. (2008). Strategy-organization configurations in corporate venture units: impact on performance and survival. Journal of Business Venturing, 23(4), 423-444. https://doi.org/10.1016/j.jbusvent.2007.04.001.

Hoang, H., \& Antoncic, B. (2003). Network-based research in entrepreneurship: a critical review. Journal of Business Venturing, 18, 165-187. https://doi.org/10.1016/S08839026(02)00081-2.

Hoang, H., \& Rothaermel, F. T. (2010). Leveraging internal and external experience: exploration, exploitation, and R\&D project performance. Strategic Management Journal, 31, 734758. https://doi.org/10.1002/smj.834.

Holmqvist, M. (2004). Experiential learning processes of exploitation and exploration within and between organizations: an empirical study of product development. Organization Science, 15(1), 70-81. https://doi.org/10.1287 /orsc. 1030.0056.

Howells, J. (2006). Intermediation and the role of intermediaries in innovation. Research Policy, 35(5), 715-728. https://doi. org/10.1016/j.respol.2006.03.005.

Ireland, R. D., Hitt, M. A., \& Vaidyanath, D. (2002). Alliance management as a source of competitive advantage. Journal of Management, 28, 413-446. https://doi.org/10.1016 /S0149-2063(02)00134-4.

Jassawalla, A. R., \& Sashittal, H. C. (1998). An examination of collaboration in high-technology new product development processes. Journal of Product Innovation Management, 15, 237-254. https://doi.org/10.1016/S0737-6782(97)00080-5.

Klotz, A. C., Hmieleski, K. M., Bradley, B. H., \& Busenitz, L. W. (2014). New venture teams: a review of the literature and roadmap for future research the NVT domain. Journal of Management, 40, 226-255. https://doi.org/10.1177 /0149206313493325.

Koch, A., Späth, J., \& Strotmann, H. (2013). The role of employees for post-entry firm growth. Small Business Economics, 41, 733-755. https://doi.org/10.1007/s11187012-9456-6.

Koza, M. P., \& Lewin, A. Y. (1998). The co-evolution of strategic alliances. Organization Science, 9(3), 255-264 www.jstor. org/stable/2640222.

Kraaijenbrink, J. (2011). Human Capital in the Resource-Based View. In A. Burton-Jones, \& J. C. Spender (Eds.), The Oxford Handbook of Human Capital. Oxford University Press, pp. 218-237. https://doi.org/10.1093 /oxfordhb/9780199532162.001.000.
Lavie, D., \& Rosenkopf, L. (2006). Balancing exploration and exploitation in alliance formation. Academy of Management Journal, 49, 797-818. https://doi.org/10.5465 /amj.2006.22083085.

Lee, S., Park, G., Yoon, B., \& Park, J. (2010). Open innovation in SMEs - an intermediated network model. Research Policy, 39, 290-300. https://doi.org/10.1016/J. RESPOL.2009.12.009.

Leiponen, A., \& Helfat, C. E. (2011). Location, decentralization, and knowledge sources for innovation. Organization Science, 22, 641-658. https://doi.org/10.1287 /orsc. 1100.0526 .

March, J. G. (1991). Exploration and exploitation in organizational learning. Organization Science, 2, 71-87. https://doi. org/10.1287/orsc.2.1.71.

Mathias, B. D., Williams, D. W., \& Smith, A. R. (2015). Entrepreneurial inception: the role of imprinting in entrepreneurial action. Journal of Business Venturing, 30(1), 11-28. https://doi.org/10.1016/j.jbusvent.2014.07.004.

Meyskens, M., \& Carsrud, A. L. (2013). Nascent greentechnology ventures: a study assessing the role of partnership diversity in firm success. Small Business Economics, 40, 739-759. https://doi.org/10.1007/s11187-011-9400-1.

Moeen, M., \& Mitchell, W. (2020). How do pre-entrants to the industry incubation stage choose between alliances and acquisitions for technical capabilities and specialized complementary assets? Strategic Management Journal, 1-40. https://doi.org/10.1002/smj.3160.

Nelson, R. R., \& Winter, S. G. (1982). An Evolutionary Theory of Economic Change. Cambridge: Harvard University Press.

Nieto, M. J., \& Santamaría, L. (2007). The importance of diverse collaborative networks for the novelty of product innovation. Technovation, 27, 367-377. https://doi.org/10.1016/J. TECHNOVATION.2006.10.001.

Okamuro, H., Kato, M., \& Honjo, Y. (2011). Determinants of R\&D cooperation in Japanese start-ups. Research Policy, 40, 728-738. https://doi.org/10.1016/J.RESPOL.2011.01.012.

Penrose, E. T. (1959). The theory of the growth in the firm. Oxford: Blackwell.

Powell, W. W., Koput, K. W., \& Smith-Doerr, L. (1996). Interorganizational collaboration and the locus of innovation: networks of learning in biotechnology. Administrative Science Quarterly, 4121125, 116-145. https://doi. org/10.2307/2393988.

Rosenbusch, N., Brinckmann, J., \& Bausch, A. (2011). Is innovation always beneficial? A meta-analysis of the relationship between innovation and performance in SMEs. Journal of Business Venturing, 26(4), 441-457. https://doi.org/10.1016 /j.jbusvent.2009.12.002.

Rothaermel, F. T. (2001). Incumbent's advantage through exploiting complementary assets via interfirm cooperation. Strategic Management Journal, 22, 687-699. https://doi. org/10.1002/smj.180.

Rothaermel, F. T., \& Deeds, D. L. (2004). Exploration and exploitation alliances in biotechnology: a system of new product development. Strategic Management Journal, 25, 201221. https://doi.org/10.1002/smj.376.

Rowley, T., D. Behrens, D. Krackhardt. 2000. Redundant governance structures: an analysis of structural and relational embeddedness in the steel and semiconductor industries. Strategic Management Journal. Special issue. 21 369-386. 
doi:https://doi.org/10.1002/(SICI)1097-0266(200003)21 :3<369::AID-SMJ93>3.0.CO;2-M.

Russo, A., \& Vurro, C. (2010). Cross-boundary ambidexterity: balancing exploration and exploitation in the fuel cell industry. European Management Review, 7(1), 30-45. https://doi. org/10.1057/emr.2010.2.

Shan, W., Walker, G., \& Kogut, B. (1994). Interfirm cooperation and startup innovation in the biotechnology industry. Strategic Management Journal, 15, 387-394. https://doi. org/10.1002/smj.4250150505.

Shi, W., \& Prescott, J. E. (2011). Sequence patterns of firms' acquisition and alliance behaviour and their performance implications. Journal of Management Studies, 48, 10441070. https://doi.org/10.1111/j.1467-6486.2010.00953.x.

Shi, W., Sun, J., \& Prescott, J. E. (2012). A temporal perspective of merger and acquisition and strategic alliance initiatives: review and future direction. Journal of Management, 38(1), 164-209. https://doi.org/10.1177/0149206311424942.

Sine, W. D., Mitsuhashi, H., \& Kirsch, D. A. (2006). Revisiting burns and stalker: formal structure and new venture performance in emerging economic sectors. Academy of Management Journal, 49, 121-132. https://doi.org/10.5465 /AMJ.2006.20785590.

Soh, P. H. (2003). The role of networking alliances in information acquisition and its implications for new product performance. Journal of Business Venturing, 18(6), 727-744. https://doi. org/10.1016/S0883-9026(03)00026-0.

Stenholm, P., \& Renko, M. (2016). Passionate bricoleurs and new venture survival. Journal of Business Venturing, 31(5), 595611. https://doi.org/10.1016/j.jbusvent.2016.05.004.

Stettner, U., \& Lavie, D. (2014). Ambidexterity under scrutiny: exploration and exploitation via internal organization, alliances, and acquisitions. Strategic Management Journal, 35(13), 1903-1929. https://doi.org/10.1002/smj.2195.

Sunduramurthy, C., Zheng, C., Musteen, M., Francis, J., \& Rhyne, L. C. (2016). Doing more with less, systematically? Bricolage and ingenieuring in successful social ventures. Journal of World Business, 51(5), 855-870. https://doi. org/10.1016/j.jwb.2016.06.005.

Tate, J. (2001). National Varieties of standardization, in: Varieties of capitalism. Oxford University Press, pp. 442-473. https://doi.org/10.1093/0199247757.003.0014.
Teubner, G. 2001. Legal irritants: how unifying law ends up in new divergences, in: Varieties of capitalism. Oxford University Press, pp. 417-441. https://doi.org/10.1093 /0199247757.003.0013.

Van Burg, E., Podoynitsyna, K., Beck, L., \& Lommelen, T. (2012). Directive deficiencies: how resource constraints direct opportunity identification in SMEs. Journal of Product Innovation Management, 29(6), 1000-1011. https://doi. org/10.1111/j.1540-5885.2012.00976.x.

Van de Ven, A. H., \& Engleman, R. M. (2004). Event- and outcome-driven explanations of entrepreneurship. Journal of Business Venturing, 19, 343-358. https://doi.org/10.1016 /S0883-9026(03)00035-1.

Vanhaverbeke, W. P. M., \& Noorderhaven, N. G. (2001). Competition between alliance blocks: the case of the RISC microprocessor technology. Organization Studies, 22(1), 130. https://doi.org/10.1177/017084060102200101.

Welter, C., Mauer, R., \& Wuebker, R. J. (2016). Bridging behavioral models and theoretical concepts: effectuation and bricolage in the opportunity creation framework. Strategic Entrepreneurship Journal, 10, 5-20. https://doi.org/10.1002 /sej.1215.

Wernerfelt, B. (1984). A resource-based view of the firm. Strategic Management Journal, 5(2), 171-180. https://doi. org/10.1002/smj.4250050207.

Wright, P. M., Dunford, B. B., \& Snell, S. A. (2001). Human resources and the resource based view of the firm. Journal of Management, 27(6), 701-721. https://doi.org/10.1177 $/ 014920630102700607$.

Zhao, E. Y., Ishihara, M., \& Jennings, P. D. (2020). Strategic entrepreneurship's dynamic tensions: converging (diverging) effects of experience and networks on market entry timing and entrant performance. Journal of Business Venturing, 35(2), 105933 . https://doi.org/10.1016/j. jbusvent.2019.04.001.

Publisher's note Springer Nature remains neutral with regard to jurisdictional claims in published maps and institutional affiliations. 